\title{
LA DEROGADA PROHIBICIÓN DE BAUTIZO Y MATRIMONIO RELIGIOSO, SIN EL TRÁMITE, APROBACIÓN Y REGISTRO PREVIO DEL ESTADO
}

THE REPEALED PROHIBITION OF BAPTISM AND RELIGIOUS MARRIAGE, WITHOUT THE PREVIOUS STATE PROCESS, APPROVAL AND REGISTER

\author{
Juan Carlos Riofrío Martínez-Villalba* \\ Jaime Baquero de la Calle Rivadeneira** \\ Pablo Marcelo Espinosa Quiroz**** \\ Juan Pablo Aguilar González ${ }^{* * * *}$
}

Resumen: El presente trabajo explica cómo ha evolucionado la regulación registral ecuatoriana relacionada con la prohibición de celebrar el bautismo y el matrimonio religioso sin previamente haber gestionado el registro de identidad y haber realizado el matrimonio civil. Curiosamente esta prohibición nació en la legislación ecuatoriana con el advenimiento del Estado laico. Varios constitucionalistas observaron desde entonces que era una tremenda contradicción proclamar la separación de Iglesia y Estado, y permitir que el Estado controle los sacramentos de la comunidad cristiana imponiendo prohibiciones. Afortunadamente, las últimas reformas

\footnotetext{
* Ph.D. Profesor de Derechos Humanos en Strathmore University (Nairobi, Kenia). http://orcid.org/0000-0003-4461-1025. jcriofrio@strathmore.edu

** Ph.D. Profesor de Derecho en la Universidad Hemisferios (Quito, Ecuador). https://orcid.org/0000-0002-7765-0621.jimmyb@uhemisferios.edu.ec

* Master of Law in U.S. Law por la Universidad de Washington (Saint Louis, Estados Unidos). Profesor de Historia del Derecho en la Universidad Hemisferios (Quito, Ecuador) y de Derecho Canónico en la Pontificia Universidad Católica del Ecuador (Quito). https://orcid.org/0000-0002-5009-7440.pablo.espinosa@ forumabogados.com

**** Graduado en Derecho por la Universidad de Navarra (España). Estudiante de Derecho de la Universidad Hemisferios (Quito, Ecuador). https://orcid.org/0000-0002-2731-5219. juanpabloaguilarg@gmail.com
} 
normativas del Registro Civil han dejado insubsistente tal prohibición. No obstante, algunos sectores eclesiásticos siguen actuando como si todavía subsistiera. Estas cuestiones se analizan con método casuístico, histórico y legal que ilustra cómo ha evolucionado la regulación y cuál es hoy la norma nacional vigente. El análisis se divide en cuatro partes. La primera, expone el problema a tratar explicando la continuidad de los usos de la Iglesia Católica, pese al cambio normativo. La segunda parte, delimita ciertos casos en los que ya no es conveniente que la Iglesia exija el certificado civil para oficiar los ritos eclesiásticos. La tercera, brinda una perspectiva históricojurídica de la legislación ecuatoriana. Finalmente, se concluye que hoy ha dejado de existir la prohibición de celebrar bautismo y matrimonio religioso sin que medien los registros estatales, y se exhorta a las autoridades cristianas a revisar si sus prácticas pueden adecuarse mejor al nuevo esquema jurídico.

Palabras clave: Bautismo, matrimonio, Registro Civil, derecho canónico, obligaciones con el Estado

Abstract: This study explains how the Ecuadorian registry regulation has evolved related to the prohibition of celebrating baptism and religious marriage without having managed the identity registry and having carried out the civil marriage previously. Curiously, this prohibition was born in the Ecuadorian legal system with the advent of the secular State. From then, some constitutionalists experts observed that it was a contradiction to proclaim the separation of Church and State, allowing the State to control the sacraments of the Christian community by imposing prohibitions. Fortunately, the latest regulatory reforms of the Public Registry have eliminated such prohibition. However, some ecclesiastical sectors continue acting as if it still exists. These matters are analyzed with a casuistic, historical, and legal method that illustrates how the regulation had evolved and which is the current standard today. The analysis is divided into four sections. The first section identifies the problem and explains the current practices within the Catholic Church, despite the regulation changes. The second section describes certain cases where it is no longer convenient for the Church to require a civil certificate to officiate ecclesiastical ceremonies. The third section provides a historical and legal perspective of the Ecuadorian legislation. Finally, it is concluded that today the prohibition against celebrating baptism and religious marriage without the mediation of State registries has ceased to exist, and the Christian authorities are urged to review whether their practices can be better adapted to the new legal framework. 
Keywords: Baptism, Marriage, Public Registry, Canon Law, Obligations with the State

Sumario. I. Introducción. II. Casos donde no conviene exigir el certificado de inscripción civil previa. III. Consideraciones jurídicas sobre la derogada prohibición de celebrar sacramentos (matrimonio o bautizo) sin contar con el registro civil previo. III.1. Sobre el deber de inscripción. III.2. Sobre la separación de bienes. IV. Conclusión. Anexo 1.

\section{INTRODUCCIÓN}

El 4 de febrero de 2016 se reformó la antigua Ley de Registro Civil que exigía la inscripción del nacimiento y la celebración del matrimonio civil, de forma previa a recibir los sacramentos de bautizo y matrimonio eclesiástico ${ }^{1}$. Mons. Juan Larrea, Jöel Hautebert y otros juristas observaron que aquello iba en contra de la libertad de religión prevista en la Constitución y en los pactos de derechos humanos. Felizmente esta disposición hoy está derogada.

Sin embargo, generalmente las autoridades eclesiásticas siguen exigiendo el certificado de inscripción civil para celebrar los sacramentos. Pensamos que esta práctica debería cambiar, especialmente en algunos casos en que ello podría resultar perjudicial a la salus animarum.

Este estudio se divide en dos secciones. En la primera sección se presentan algunos casos en los que parece claro que convendría que los pastores o autoridades religiosas permitan celebrar los sacramentos de una manera más sencilla, sin exigir a los contrayentes el certificado de inscripción civil (que ya no lo exige la legislación ecuatoriana). En la segunda sección se explican las cuestiones jurídicas sobre la reforma de la ley ecuatoriana, y sus efectos en el derecho de la Iglesia.

\footnotetext{
${ }^{1}$ La disposición tiene sus antecedentes en la Ley de Matrimonio Civil de 1902, por la que «el Estado arrebató a los eclesiásticos la capacidad de realizar estas ceremonias con efectos legales» (Ayala, 1996, p. 13). Tal acto de fuerza fue fuertemente criticado desde entonces por la doctrina. Así, por ejemplo, Cuesta (1902) observó que «una ley civil que (...) pretende reglar su validez, contradice la doctrina de la Iglesia, usurpa sus derechos inalienables, y en la práctica, pone en una misma categoría el concubinato y el, sacramento del matrimonio, sancionando ambos como igualmente legítimos» (p. 9).
} 


\section{CASOS DONDE NO CONVIENE EXIGIR EL CERTIFICADO DE INSCRIPCIÓN CIVIL PREVIA}

En primer lugar, hemos de recordar que actualmente para bautizar ya no tiene sentido pedir que la persona acuda al Registro Civil para sacar la cédula. Desde el año 2016 esto simplemente ya no es requerido por la ley².

En segundo lugar, conviene considerar algunos casos de personas que viven en una situación contraria a su conciencia y religión (conviven con quien no es su cónyuge) simplemente por temas burocráticos. Se trata de personas que en la ley canónica no tienen ningún obstáculo para casarse, pero no lo hacen porque la burocracia estatal y su costo económico los disuaden de tramitar los documentos públicos para casarse por la Iglesia. Veamos cuatro ejemplos:

- Piénsese en quien se ha casado solo por lo civil —no por la Iglesiay luego convive de hecho con otra persona, con quien desea vivir para siempre. De repente, un día sufre una conversión espiritual y quiere poner todos sus papeles bien ante Dios: según la ley ecuatoriana esta persona debería divorciarse y casarse nuevamente, mientras según la ley canónica solo debería casarse con la segunda pareja. En realidad, esta persona nunca ha contraído matrimonio válido (bajo la ley eclesiástica), porque nunca lo ha hecho ante la Iglesia. Normalmente las personas que se encuentran en este caso tocan las puertas del párroco para casarse religiosamente, pero el párroco suele no prestarles auxilio y más bien les pide que primero se divorcien por lo civil.

Muchísimas personas, al ver el largo proceso civil que tienen que pasar (pagar abogados, ir ante jueces y notarios, tener que conversar con la exesposa con la que aún mantiene desavenencias por el tema de los hijos, etc.), y el tiempo que esto demora, simplemente prefieren seguir viviendo en concubinato.

- Un segundo caso es el de quien tiene su excónyuge (“ex” según la ley nacional) viviendo en el extranjero, y desea casarse con la pareja con la que convive en el Ecuador. Esta persona desea tramitar el divorcio civil para poder casarse (por el Estado y por la Iglesia) con la segunda pareja, pero por su ausencia le resulta demasiado difícil

\footnotetext{
${ }^{2}$ Para ahondar sobre el detalle de la reforma, de sus efectos y de la actual no necesidad de realizar trámites previos en el Registro Civil, cfr. Baquero, 2019.
} 
lograr tal sentencia de divorcio. Si no se le concediera casarse fácilmente por la Iglesia con la segunda pareja con la que convive, a la final sería el mismo párroco quien le impediría a esa pareja vivir bien ante Dios. Quien pone requisitos no exigidos por la ley para casarse, obstaculiza el ejercicio del derecho matrimonio propio de los fieles, y colabora en cierta medida para que ellos sigan viviendo de forma irregular.

- Un tercer caso es el del quien desearía tramitar el divorcio civil para poder casarse (por el Estado y por la Iglesia) con otra persona, pero por las desavenencias entre la pareja el proceso de divorcio se alarga más de lo esperado. Ocurriría lo mismo: la persona seguiría conviviendo con quien no es su cónyuge ante Dios, pues aunque quieren casarse por la Iglesia, no pueden porque el párroco — sin motivo en la ley ecuatoriana - le niega el derecho canónico al matrimonio.

- Finalmente está el caso de personas que viven en comunidades rurales, alejadas de las oficinas de Registro Civil, y que no suelen estar culturalmente relacionadas con las estructuras del Estado ${ }^{3} . \mathrm{Si}$ un párroco les pide que primero se casen ante el Estado, sucederían dos cosas: primero, el párroco les estaría mostrando que el matrimonio civil tiene algún valor ante la Iglesia, y, segundo, muchos optarán por no ir a tales oficinas que les resultan extrañas, que significa gastar recursos económicos ${ }^{4}$ y requieren un tiempo del

\footnotetext{
${ }^{3}$ La República del Ecuador, acorde con el Plan Nacional de Descentralización, está dividida en 1499 parroquias, de las cuales 359 son urbanas y 1140 son rurales (Ministerio de Obras Públicas, 2016, pp. 1-20). Esto indica que el Registro Civil, Identificación y Cedulación solo tiene presencia concreta en el $13 \%$ de las parroquias del país. Si bien es cierto que las oficinas públicas se ubican en las parroquias con mayor población, esto no obsta para que un gran número de ecuatorianos tenga que movilizarse fuera de su parroquia de origen, para realizar trámites cuya competencia está atribuida al Registro Civil.

El Registro Civil cuenta con muy pocas agencias en poblaciones rurales. Año a año se realizan jornadas en las que el registro público se moviliza a parroquias rurales de distintas provincias para atender a miles de ciudadanos. Por ejemplo, el año pasado, solo en diez parroquias de la provincia de Santo Domingo las jornadas rurales atendieron a más de 1500 personas (Diario La Hora, 2019, párr. 21).

${ }^{4}$ Existen 951 parroquias rurales (de 1140), que superan el umbral del 50\% por necesidades básicas insatisfechas, que las ubica en el umbral entre la pobreza y la pobreza extrema. Según el estudio, gran parte de las parroquias alcanzan la calificación de pobreza extrema: «Si bien no es una novedad que la mayor parte de la población pobre está en el área rural,
} 
que no siempre se dispone. Una vez más, un porcentaje grande de los fieles preferirá seguir viviendo en concubinato. El obstáculo aquí es el párroco, que sin exigirlo la ley ecuatoriana, exige que se cumpla con el registro previo del matrimonio civil.

\section{CONSIDERACIONES JURÍDICAS SOBRE LA DEROGADA PROHIBICIÓN DE CELEBRAR SACRAMENTOS (MATRIMONIO O BAUTIZO) SIN CONTAR CON EL REGISTRO CIVIL PREVIO}

A inicios del siglo pasado, la reforma liberal aprobó el matrimonio civil en el Ecuador. Como los ecuatorianos estaban acostumbrados a casarse solo ante la Iglesia católica, el legislativo prohibió - de una manera contraria a los derechos humanos - el matrimonio católico si previamente no se realizaba el matrimonio civil. La prohibición creó una práctica en la Iglesia católica, poco saludable desde nuestro punto de vista, que felizmente ha quedado derogada desde el año 2016. Pasamos a ver aquí los pormenores del asunto.

\section{III.1. Sobre el deber de inscripción}

La única norma del ordenamiento jurídico ecuatoriano que prohibía a los cristianos realizar el sacramento del bautismo o del matrimonio antes de que se inscribiera el nacimiento o el matrimonio en el Registro Civil era la siguiente:

Ley General de Registro Civil Identificación y Cedulación, ${ }^{5}$ art. 23.Precedencia de la inscripción a las ceremonias religiosas o a la inhumación.- La inscripción de nacimiento y la de matrimonio deberán preceder a las ceremonias religiosas correspondientes, salvo peligro de muerte. Los ministros de cualquier religión que contravinieren este precepto serán sancionados por el Jefe de Registro Civil, Identificación y Cedulación respectivo, con multa de un mil a cinco mil sucres.

No podrá procederse a la inhumación o sepultura de un cadáver antes de que se inscriba la defunción, y el infractor será sancionado con la multa prevista para los casos indicados en el inciso anterior.

cabe resaltar que según el indicador de pobreza por NBI, casi el total de parroquias rurales presentan porcentajes que están en el rango de 70\% a 100\%» (Torres, 2004, p. 31).

${ }^{5}$ La ley se publicó por Decreto Supremo ${ }^{\circ} 278$, publicado en el Registro Oficial $n^{\circ} 70$ de 21-IV-1976. 
Esta Ley estuvo en vigor hasta el 4 de febrero de 2016, día en el cual entró en vigor la Ley Orgánica de Gestión de la Identidad y Datos Civiles, que al final dice:

\section{DISPOSICIONES DEROGATORIAS}

UNICA. Deróguense la Ley General de Registro Civil Identificación y Cedulación publicada en el Registro Oficial No. 70 de 21 de abril de 1976 (ver...) y las demás normas de igual o inferior rango que se opongan a la presente Ley.

Actualmente no hay ninguna norma en el ordenamiento jurídico nacional que impida realizar ningún sacramento o ceremonia religiosa sin cumplirse antes algún género de requisitos civiles. En este sentido, el profesor francés Joël Hautebert $(2016)^{6}$, al comparar el sistema registral francés y ecuatoriano, señaló que el Ecuador ha evolucionado para bien al derogar esta antigua norma tan criticada por la doctrina ecuatoriana (especialmente por el Dr. Juan Larrea Holguín) y que actualmente ya no existe ninguna prohibición en este sentido para administrar los sacramentos.

Tal prohibición fue tachada de inconstitucional por muchos célebres juristas, pues no se condice con la naturaleza laica del Estado donde, ni los poderes estatales pueden controlar los asuntos de la Iglesia, ni las autoridades eclesiásticas entrometerse en los asuntos de Estado. La laicidad implica una sana separación y autonomía de la Iglesia y del Estado ${ }^{7}$. Sobre este asunto específico, el Dr. Juan Larrea Holguín observó en esa época que «la limitación de la libertad es gravísima en sí misma, por contrariar un principio fundamental de Derecho Natural, Internacional y Constitucional, pero, además, resulta gravísima para la conciencia de los católicos, porque según nuestra fe, el Bautismo es indispensable para la salvación eterna» (1995, pp. 16-17).

Por tanto, desde el punto de la ley ecuatoriana consideramos que ya no tiene sentido que los ministros religiosos exijan a quienes desean casarse por la Iglesia la inscripción del matrimonio en el Registro Civil, ni menos el divorcio civil. Sin duda se puede recomendar, pero ni esto parece conveniente si se pudiera retrasar el matrimonio eclesiástico de dos personas que viven en concubinato.

\footnotetext{
${ }^{6}$ Adjuntamos en el Anexo I un extracto del artículo, justamente la parte que habla sobre este tema.

${ }^{7}$ La laicidad del Estado ha quedado recogida desde la Constitución de 1906 y se mantiene hasta la Constitución de 2008.
} 


\section{III.2. Sobre la separación de bienes}

Otra figura que ha evolucionado en los últimos años es la relacionada con la separación de bienes y las capitulaciones matrimoniales. Aunque inicialmente el Código Civil preveía la figura de la "separación de los cónyuges", esta fue derogada hace ya décadas, lo que ocasionó que los cónyuges católicos que deseaban vivir separados, administrando cada uno sus bienes, tuvieran que recurrir al divorcio civil; sin este, la sociedad conyugal creada ipso iure por el matrimonio, no se podía disolver.

Actualmente la cuestión ha evolucionado mucho, desde que se ha ampliado el campo de las capitulaciones matrimoniales, que son contratos entre los cónyuges que permiten disolver, dividir o administrar como deseen la sociedad conyugal durante el matrimonio. En concreto, el Código Civil vigente dice al respecto:

Art. 189.- La sociedad conyugal se disuelve:

1. Por la terminación del matrimonio;

2. Por sentencia que concede la posesión definitiva de los bienes del desaparecido;

3. Por sentencia judicial, a pedido de cualquiera de los cónyuges; y,

4. Por la declaración de nulidad del matrimonio.

En los casos de separación parcial de bienes continuará la sociedad en los bienes no comprendidos en aquella.

Art. 221.- Los cónyuges que mediante sentencia ejecutoriada hubieren obtenido la separación conyugal judicialmente autorizada, conservarán todos los derechos, obligaciones y efectos inherentes a este estado.

Los cónyuges separados podrán, en cualquier tiempo, de mutuo acuerdo, solicitar al juez que declare terminada la separación conyugal; para ello, bastará la declaración de la voluntad conjunta de los cónyuges, por escrito, ante el juez competente, quien, cerciorándose de la verdad y libertad de la declaración; luego de reconocidas las firmas, pronunciará sentencia, sin más trámite, la misma que se inscribirá en el registro civil y en el de la propiedad del respectivo cantón, tomándose nota de esta sentencia al margen de la que autorizó la separación. En virtud de la sentencia se restablecerán los derechos y las obligaciones entre los cónyuges y el régimen de la sociedad conyugal, si no lo establecieren en capitulaciones matrimoniales.

También podrán demandar el divorcio en cualquier momento, por mutuo consentimiento o por las causales determinadas en el Art. 110.

Aunque hoy aún sigue derogada la figura de la "separación de los cónyuges", ha aparecido al menos la posibilidad de la "separación de los bienes". Consideramos que para un matrimonio católico que desee separarse viviendo según los postulados de su fe, no conviene seguir "aconsejándole" 
que se divorcie por lo civil para que los cónyuges tengan autonomía de bienes, sino que, por el contrario, debería sugerírsele que pacten unas capitulaciones matrimoniales para dar efectos civiles a su decisión de separarse.

\section{CONCLUSIONES}

De lo visto, extraemos las siguientes conclusiones:

1. Es claro desde todo punto de vista que la legislación ecuatoriana ya ha dejado de exigir la inscripción previa en el Registro Civil, para poder celebrar los sacramentos de bautizo y matrimonio. Si los sacerdotes lo siguen exigiendo, es por una práctica de casi un siglo donde estuvo vigente la antigua ley, y no por una imposición de la autoridad civil ecuatoriana.

2. La ley antigua fue condenada por Mons. Larrea Holguín y otros juristas, por atentar contra la libertad religiosa. Hoy felizmente ya ha sido derogada. En nuestra modesta opinión, no tiene ningún sentido que esa práctica contraria a los derechos humanos siga exigiéndose por las autoridades eclesiásticas.

3. Consideramos que si se facilita que las personas celebren el matrimonio eclesiástico sin exigir la previa inscripción civil - ya no exigida por la ley ecuatoriana-, se consiguen varias cosas:

- Primero, se evitará que muchos fieles sigan viviendo irregularmente.

- Los párrocos dejarán de ser motivo para que ciertas uniones de hecho se prolonguen.

- Se mostrará mejor que el matrimonio civil no tiene el valor que la gente piensa.

Por tanto, aconsejamos vivamente a las autoridades eclesiásticas revisar las prácticas a las que la antigua legislación ecuatoriana nos tenía acostumbrados. 


\section{REFERENCIAS}

Ayala Mora, E. (1996). El laicismo en la Historia del Ecuador. Revista Ecuatoriana de Historia, 8, 3-32.

Baquero de la Calle Rivadeneira, J. (2019). Laicidad y Libertad Religiosa en el Ecuador. En González Merlano, G. (ed.), Principio de laicidad y libertad religiosa. El rol del Estado en la sociedad plural. Universidad Católica del Uruguay.

Cuesta, J. (1902). Breves consideraciones sobre la ley del matrimonio civil. Imprenta El Bien Público.

Diario La Hora (17-IX-2019). Servicios del Registro Civil llegan a las parroquias. https://www.lahora.com.ec/

Ecuador (2008). Constitución de la República del Ecuador, Decreto Legislativo $n^{\circ} 0$, Registro Oficial $n^{\circ} 449$.

Ecuador (1906). Constitución Política de la República del Ecuador.

Ecuador (2016). Ley Orgánica de Gestión de la Identidad y Datos Civiles, Registro Oficial $n^{\circ} 684$.

Ecuador (1902). Ley de Matrimonio Civil del Ecuador, Registro Oficial nº 317.

Ecuador (1976). Ley General de Registro Civil, Identificación y Cedulación, Decreto Supremo ${ }^{\circ} 278$, Registro Oficial $n^{\circ} 70$.

Ecuador. Ministerio de Obras Públicas (2016). Provincias-Cantones-Parroquias del Ecuador (pp. 1-20). https://www.obraspublicas.gob.ec/

Hautebert, J. (2016). Registro civil y secularización. Comparación entre Ecuador y Francia. Ius Humani. Revista de derecho, 5, 259-272. DOI: https://doi.org/10.31207/ih.v5i0.116.

Larrea Holguín, J. (1988). La Iglesia y el Estado en el Ecuador. Casa de la Cultura Ecuatoriana "Benjamín Carrión".

Larrea Holguín, J. (1995). La libertad para ejercer la religión. Revista Jurídica, 13-20.

Larrea Holguín, J. (1998). Religión y derecho. Poligráfica C.A.

Santa Sede (1862). Concordato celebrado entre su Santidad Sumo Pontífice Pio IX y el Presidente de la República del Ecuador. http://repositorio.casadelacultura.gob.ec/

Torres, M. (2004). Las Juntas Parroquiales Rurales del Ecuador como nueva instancia de gobierno seccional autónomo: ventajas, limitaciones y perspectivas. Facultad Latinoamericana de Ciencias Sociales.

Valero, P. (2014). "Un proyecto de modernidad católico: el Ecuador de García Moreno". De Raíz Diversa, 1 (2), 155-182. 


\section{ANEXO 1}

\section{Extracto del escrito del catedrático de Historia del Derecho de la Universidad de Anger (Francia), Joël Hautebert. "Registro civil y secularización. Comparación entre Ecuador y Francia", en Ius Humani. Revista de derecho, v. 5 (2016).}

[página 261] (...) Esta problemática general, que concierne a todo el mundo católico, se puede estudiar en los escritos de Mons. Juan Larrea Holguín a través de un punto de derecho particular sobre el cual el Arzobispo de Guayaquil vuelve a menudo, o sea la obligación de la inscripción en el Registro Civil antes de tener recurso a los sacramentos de bautismo y de matrimonio. Esta obligación que apareció en Ecuador al principio del siglo XX existía ya en Francia (para el matrimonio) desde hace un siglo, o sea desde la revolución, que sirvió de modelo político y jurídico a muchos países, sobre todo en perspectivas laicistas, dado que es la revolución francesa la que inició esta práctica del matrimonio civil obligatorio. Conviene estudiar si las diversas maneras con las cuales la Iglesia trató durante dos siglos de defender su libertad, de definir sus relaciones con los Estados y con el derecho vigente en los países y en el orden internacional influyeron sobre la cuestión concreta del Registro Civil.

[página 263] En Ecuador, después de la revolución liberal de 1895, sopló un viento de descristianización análogo ${ }^{8}$. Según Mons. Larrea (1998, p. 48), Ecuador conoció en los años que siguen una «avalancha legislativa anticristiana» ${ }^{9}$. Entre ellas, la ley de 29 de octubre de 1900 estableció el registro civil público. Dos años después, el 3 de octubre de 1902, fue votada una ley que legalizaba el divorcio [página 264] y creaba el matrimonio civil $^{10}$. Según el Arzobispo de Guayaquil, «la ley de matrimonio civil del 28 de octubre de 1902, preparada ya por la de Registro Civil, del 29 de octubre

\footnotetext{
${ }^{8}$ Conviene saber que al mismo tiempo en Francia, una vez más, la Iglesia padeció una política extremadamente laicista durante la Tercera República, que separó de nuevo la Iglesia del Estado, abrogando el Concordato de 1801, del cual hablaremos más adelante.

${ }^{9}$ Afirma también Larrea, que: «En conclusión, el conjunto de leyes y decretos del primer período alfarista revelan el espíritu sectario del nuevo régimen implantado primero dictatorialmente mediante la fuerza de las armas y luego consolidado por el fraude electoral; sistema contrario al sentir inmensamente mayoritario de la nación y que, por la violencia y prepotencia de sus jefes, llegó a inauditas violaciones del Derecho Eclesiástico, del Derecho Internacional, del Derecho Constitucional y de la razón natural» (1998, p. 55).

${ }^{10}$ Ambas leyes entraron en vigor el 1-I-1901 y el 1-I-1903, respectivamente.
} 
de 1900, ponía un abismo más, para el buen entendimiento con la Iglesia» (Larrea, 1988, p. 57). Como en Francia durante la revolución, la translación del estado civil acompaña lógicamente la creación del matrimonio civil y la legalización del divorcio. Pero, sobre todo, la inscripción debe preexistir al sacramento. El art. 23 de la ley de 1900 dice que «la inscripción de nacimiento y la de matrimonio deberán preceder a las ceremonias religiosas correspondientes, salvo peligro de muerte». Mons. Larrea (1995, p. 16) afirma:

«La limitación de la libertad es gravísima en sí misma, por contrariar un principio fundamental de Derecho Natural, Internacional y Constitucional, pero, además, resulta gravísima para la conciencia de los católicos, porque según nuestra fe, el Bautismo es indispensable para la salvación eterna, y el sacramento del matrimonio es necesario para la convivencia conyugal bajo pena de pecado mortal. Pues bien, estos decisivos actos de la práctica del culto, quedan impedidos por la ley».

(...) Mons. Larrea (1995, pp. 16-17) observaba: [265]

«En este punto, cabe señalar que la ley originaria, la de 1901, sancionaba también con prisión al sacerdote que realizaba estas ceremonias religiosas antes de la inscripción civil, y la multa era más grave, en relación con el valor de la moneda en esa época. Ahora la multa, ha llegado a ser pequeña, por la desvalorización del sucre, pero no deja de ser una sanción vergonzosa e injusta».

Esta sanción estaba prevista en el mismo art. 23, que señalaba que «los ministros de cualquier religión que contravinieren este precepto serán sancionados por el Jefe de Registro Civil, Identificación y Cedulación respectivo, con multa de mil a cinco mil sucres». En Francia también, encontrábamos ese tipo de disposición penal. (...)

[269] (...) una reciente evolución muy importante del derecho ecuatoriano con respecto al Registro Civil protege a la Iglesia católica de la existencia futura de esa espada de Damocles. En efecto, la Ley Orgánica de Gestión de la Identidad y Datos Civiles ${ }^{11}$ de 4 de febrero de 2016 no menciona la antigua obligación (prevista en el art. 23 de la ley de 1900 y de 1976). El art. 11 relativo a la obligatoriedad simplemente prescribe que «la inscripción o [270] registro de los hechos y actos relativos al estado civil identificación de las personas tienen el carácter de obligatorio en el territorio ecuatoriano», sin mencionar ninguna anterioridad sobre el sacramento de matrimonio. Además, la única norma transitoria precisa: «Deróguense la

\footnotetext{
${ }^{11}$ Esta ley sustituye a la antigua Ley de Registro Civil, Identificación y Cedulación (primera disposición reformatoria).
} 
Ley General de Registro Civil Identificación y Cedulación publicada en el Registro Oficial n ${ }^{\circ} 70$ de 21 de abril de 1976 y las demás normas de igual o inferior rango que se opongan a la presente Ley». En los tiempos actuales, vistas las evoluciones legislativas en muchos países, la separación clara entre el sacramento del matrimonio y el matrimonio civil garantiza no solamente la libertad de la Iglesia, sino también la imposibilidad de subvertir, un día, el matrimonio católico. 